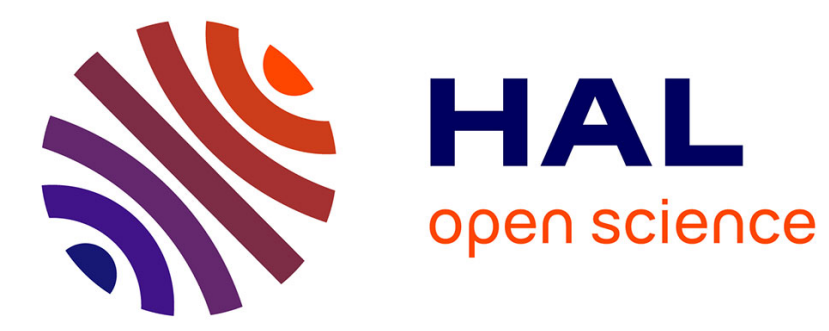

\title{
Processing of temperature field in chemical microreactors with infrared thermography
}

Christophe Pradere, Mathieu Joanicot, Jean-Christophe Batsale, Jean Toutain, Christophe Gourdon

\section{To cite this version:}

Christophe Pradere, Mathieu Joanicot, Jean-Christophe Batsale, Jean Toutain, Christophe Gourdon. Processing of temperature field in chemical microreactors with infrared thermography. Quantitative InfraRed Thermography Journal, 2006, 3 (1), pp.117-135. 10.3166/qirt.3.117-135 . hal-00742263

\section{HAL Id: hal-00742263 \\ https://hal.science/hal-00742263}

Submitted on 16 Oct 2012

HAL is a multi-disciplinary open access archive for the deposit and dissemination of scientific research documents, whether they are published or not. The documents may come from teaching and research institutions in France or abroad, or from public or private research centers.
L'archive ouverte pluridisciplinaire HAL, est destinée au dépôt et à la diffusion de documents scientifiques de niveau recherche, publiés ou non, émanant des établissements d'enseignement et de recherche français ou étrangers, des laboratoires publics ou privés. 


\title{
Processing of temperature field in chemical microreactors with infrared thermography
}

\author{
Pradere $^{1 *}$ C., Joanicot ${ }^{1}$ M., Batsale ${ }^{2}$ J.C., Toutain $^{2}$ J., C. Gourdon ${ }^{3}$. \\ ${ }^{1}$ LoF, FRE 2771, 178 avenue du Docteur Schweitzer, 33608 Pessac. \\ ${ }^{2}$ TREFLE- ENSAM ; Esplanade des Arts et Métiers-33405 Talence cedex-France \\ ${ }^{3}$ LGC, UMR 5503, BP 1301, 5 rue Paulin Talabot, 31106 Toulouse Cedex 1.
}

\begin{abstract}
:
This work is devoted to the first analysis of temperature fields related to chemical microfluidic reactors. The heat transport around and inside a microchannel is both convective and diffusive with spatial distribution of source terms and strong conductive effects in the channel surrounding. With simplified assumptions, it is shown that Infrared thermography and processing methods of the temperature frames allow to estimate important fields for the chemical engineers, such as the heating source distribution of the chemical reaction along the channel. A validation experiment of a temperature field processing method is proposed with Joule effect as calibrated source term and non reactive fluids. From such previous experiment, a Peclet field is estimated and used in a further step in order to study an acid-base flow configuration.
\end{abstract}

KEY WORDS: Chemical microreactors, Microfluidic, Inverse Methods, Temperature field processing, MEMS, Microsystems

Received 23 January 2006 ; accepted for publication 14 April 2006

QIRT Journal Volume $3-\mathrm{n}^{\circ} 1 / 2006$, pages 117 to 135 


\section{Introduction}

Microfluidic chemical reactors are one of the very promising tools given by MEMS (micro-electro-mechanical systems). One application of MEMS consists in investigating the chemical reactions in fluid flow situations in micro channel. The small size is suitable to master the mixing of the reactants with very low Reynolds laminar flows. It is also very convenient to use a few amount of products and to be able to easily and quickly test a great number of reaction configurations (Tabeling, 2003). A generally tested situation in such devices is the coflow (Salmon et al., 2004) where the reactants are mixed by mass diffusion during a laminar contact flow.

In order to develop and optimize the MEMS, the temperature information in such devices is among the most important parameters. At this moment, only a few studies are related to such preoccupations. One way consists in developing localised temperature microsensors (Köhler et al., 1998). Very recently, an other way consisting in measuring the infrared emission field of the surface of the system without contact has been implemented (Möllmann et al., 2004). Unfortunately, such pioneer work is only devoted to a qualitative analysis of the temperature fields. Even if the accuracy of the absolute temperature field is difficult due to the poor knowledge of the radiative properties (spectral emissivity, transparency, etc.) of the investigated surface, the quantitative interpretation of such fields is possible with previous calibrations and simplified heat transfer models.

The main objective of the present work is then to propose one example of estimation method in such cases. The aim is here to access to the source term distribution inside a channel containing chemical microreactions. It will consist in inverting the non calibrated temperature field inside and outside the channel with simplified models.

In a first step, it is absolutely necessary to globally estimate the main parameters of the thermal system around the channel, instead of trying to estimate the thermophysical properties of the walls (thermal diffusivity, flow rate in the channel or also the corresponding size of the pixels of the image).

A calibration experiment is proposed. It will consist in considering the perturbation of steady state images at different flow rates in the case of pure water and heating by Joule effect, instead of chemical reaction. A Peclet distribution along the channel is then estimated and it is also possible to validate a simplified model which links the temperature field and a calibrated source term distribution inside the channel. Such nondimensional Peclet number will be able to represent the comparative effects of diffusion, transport and size calibration.

The Peclet information is then used to study a complete acid-base chemical reaction. The results will be discussed at different flow rates. 


\section{Experimental device}

\subsection{Microchip production}

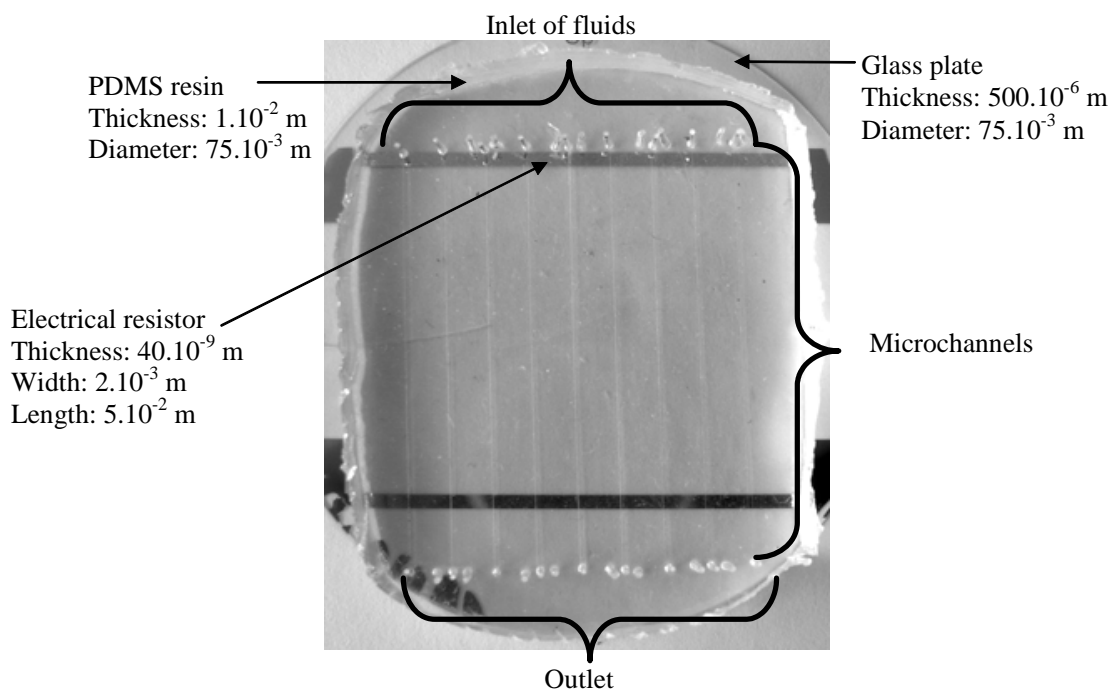

Figure 1: Microfluidic chip, view from the PDMS side.

In a microreactor (figure 1) the chemical components are mixed by the mass diffusion in the fluid flow. The study of a lot of practical situations with various networks and sizes of channels is now easily implementable by the way of fabrication techniques at microscale.

The main steps of the fabrication from an elastomeric medium (polydimethylsilexan, PDMS) are (Duffy et al., 2004):

(i) design of the complete network of microchannels by computer

(ii) printing of the network on a transparent plate

(iii) photolithography process with the printed plate used as a mask in order to create a positive mould (with positive relief) of photoresistive resin.

(iv) reproduction of the microchannel network (hollowed or with negative relief) inside PDMS resin,

(v) sticking of the PDMS block containing the microchannel network to a closing substrate (glass or silicium) after ozone oxidation. 
This a convenient and cheap mean of production of microfluidic chip.

The characteristic diameter of the microchannels is about 10 to $1000 \mu \mathrm{m}$ which corresponds to such volumes as $1 \mathrm{nl}$ to $10 \mu \mathrm{l}$ per centimeter of channel length.

\subsection{Measurement device}

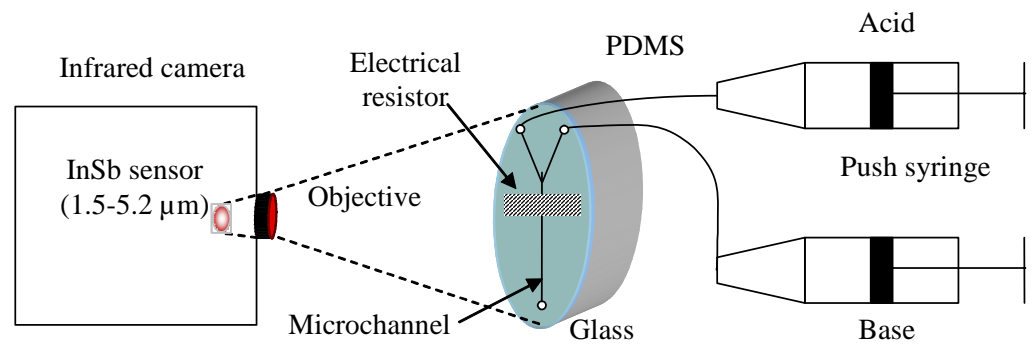

Figure 2: Measurement device

The measurement device is shown on figure 2. An infrared camera CEDIP, JADE MWIR J550, In-Sb focal plane array of detectors (1.5-5.2 $\mu \mathrm{m}$, $240 * 320$ pixels, pitch $30 \mu \mathrm{m}$ ) with a $25 \mathrm{~mm}$ objective MWIR F/2 (space resolution about $200 \mu \mathrm{m}$ ) and a G3 MWIR F/2 microscope objective (space resolution about 25 $\mu \mathrm{m})$ is in front of the micro reactor.

One of the chemical reaction classically tested is acid-base. The flow is supplied with push syringe systems at different rate from 250 to $5000 \mu \mathrm{l} / \mathrm{h}$.

The glass layer (thickness $500 \mu \mathrm{m}$ ) is of Corning Pyrex 7740 type and transparent in the range of detection of the camera (see the transmission curve on figure 3 ). 


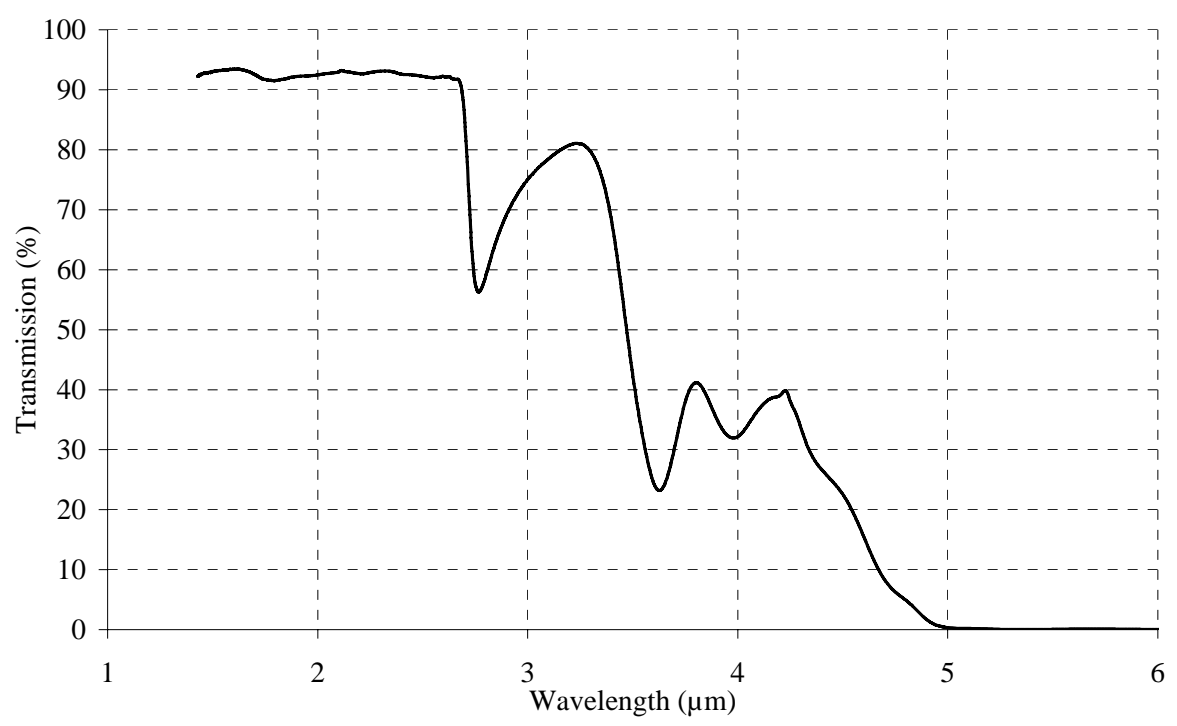

Figure 3: Transmission curve of pyrex 7740 glass plate of $500 \mu \mathrm{m}$ thickness.

Other glasses as foturan or silicium wafers are also transparent and convenient for such experiments.

The measurement of the field of absolute temperature by thermography is difficult (ignorance of emissivity, disturbances by reflections...). The images obtained thereafter are only fields proportional to absolute temperatures at the interface between PDMS and glass layer. As the thermal conductivity of Pyrex is $1.2 \mathrm{~W} \cdot \mathrm{m}^{-1} \cdot \mathrm{K}^{-1}$ and PDMS is $0.17 \mathrm{~W} \cdot \mathrm{m}^{-1} \cdot \mathrm{K}^{-1}$ we can assumed that the non calibrated measured temperature field is only influenced by the $2 \mathrm{D}$ conduction inside the glass plate and the convective transport inside the channel. In order to avoid non uniformity effects (array of sensors and reflection disturbance) the transient images are systematically corrected by the initial temperature distribution (without heating or fluid flow).

\section{Calibration experiment and Peclet field estimation}

\section{3-1 Direct models}

In order to realize a calibration experiment a thin heating resistor is deposited at the entrance of the channel (see figure 4). The electrical resistor is first deposited on the glass and then recovered by a thin layer $(5 \mu \mathrm{m})$ of PDMS and finally a PDMS (with electrical resistor)-PDMS (with microchannel) link is realised. 


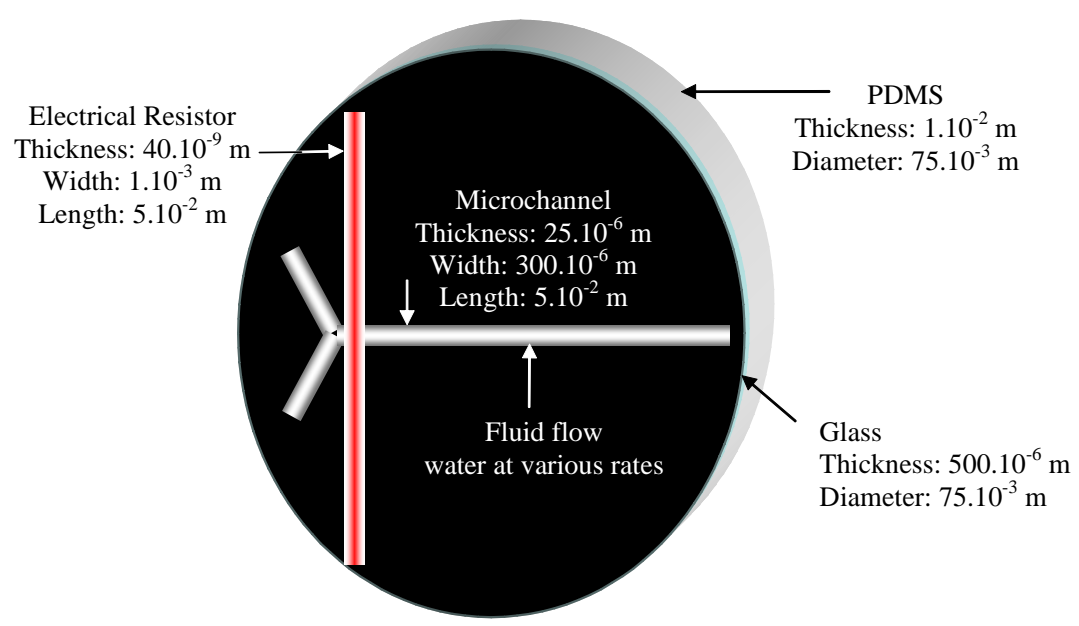

Figure 4: Heating device for the calibration method (electrical resistor and water)

Then, the electrical resistor is heated by a stabilized power supply ( $\mathrm{P}=100 \mathrm{~mW}$ ). At steady state, 2000 images are recorded and averaged with the infrared camera.

The temperature field measured without any fluid flow in steady state on the front surface of the glass plate is shown on figure 5 .

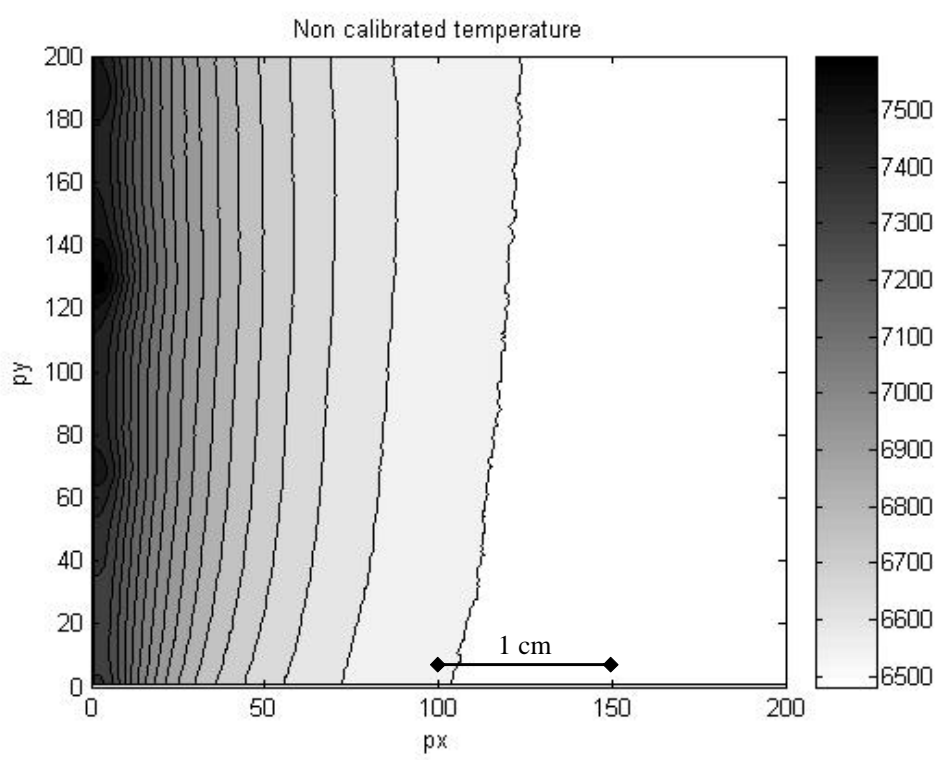

Figure 5: Steady temperature field when no fluid flows inside the channel.

Such field is giving information about the heat transfer mode inside the global system. The width of the heating resistor is about $(1 \mathrm{~mm})$ corresponding to (7 
pixels). The glass plate is much more conductive $\left(1.2 \mathrm{~W} \cdot \mathrm{m}^{-1} \cdot \mathrm{K}^{-1}\right)$ than PDMS $(0.1$ $\left.\mathrm{W} \cdot \mathrm{m}^{-1} \cdot \mathrm{K}^{-1}\right)$. Then, it can be assumed that the heat distribution is $2 \mathrm{D}$ in the glass plate (with low lateral heat losses) such as:

$$
\frac{\partial^{2} T^{0}}{\partial x^{2}}+\frac{\partial^{2} T^{0}}{\partial y^{2}}-H(x, y) T^{0}+\phi(x, y)=0
$$

Where: $T^{0}$ : temperature $(K) ; x$ : space coordinate; $H$ : heat losses parameter $\left(\mathrm{m}^{-2}\right)$; $\phi(x, y)$ local source term $\left(K . m^{-2}\right), \Delta x$ : pixel size $(m)$.

In the case of temperature image processing, the 2D finite differences approximation of the previous expression by considering the non calibrated temperature signal $T_{i, j}^{0}$ of one pixel at node $i, j$ is such as:

$\left(T_{i+1, j}^{0}+T_{i-1, j}^{0}+T_{i, j+1}^{0}+T_{i, j-1}^{0}-4 T_{i, j}^{0}\right) \frac{1}{\Delta x^{2}}-H_{i, j} T_{i, j}^{0}+\phi_{i, j}=0$

Where: $\Delta x$ : pixel size $(m)$.

The laplace operator applied on the temperature field $\left(\Delta T^{0}=\left[T_{i+1, j}^{0}+T_{i-l, j}^{0}+T_{i, j+1}^{0}+T_{i, j-1}^{0}-4 . T_{i, j}^{0}\right]\right)$ is shown on figure 6. The space step $\Delta x$ (size of a square pixel) is small and allow to locally neglect the lateral heat losses (such as $\frac{4}{\Delta x^{2}}>H$ ). Such expression is valuable if $\Delta x$ is as small as possible (verified here with the high resolution of the camera). 




Figure 6.a: Laplace operator applied on the previous temperature field (figure 5)

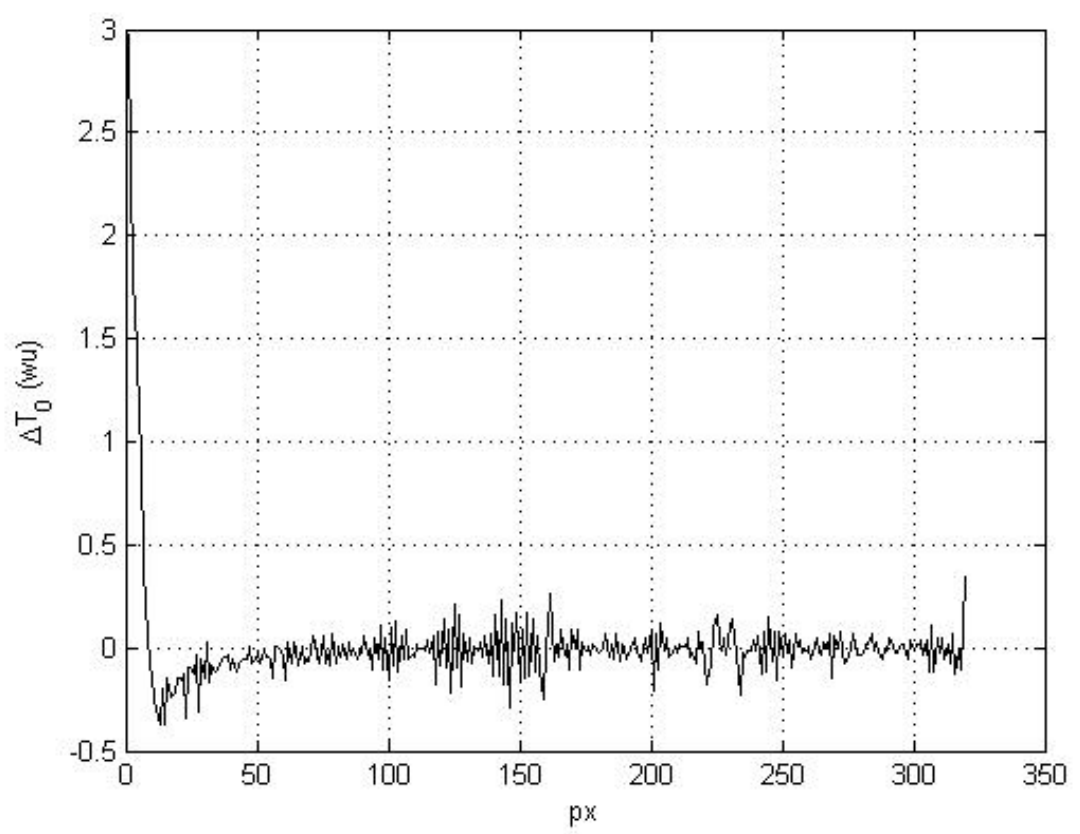

Figure 6.b: 1D curve relative to figure 6.a

One other proof to locally neglect the lateral heat losses is to consider figure 6-b where it is well observed that the losses are negligible compared to the laplacian 
term ( $\Delta T^{0} \approx 0$ out of the electrical heater source term). The temperature field $T_{0}$ of figure 5 is also a reference temperature field to be compared to experiments with fluid flow.

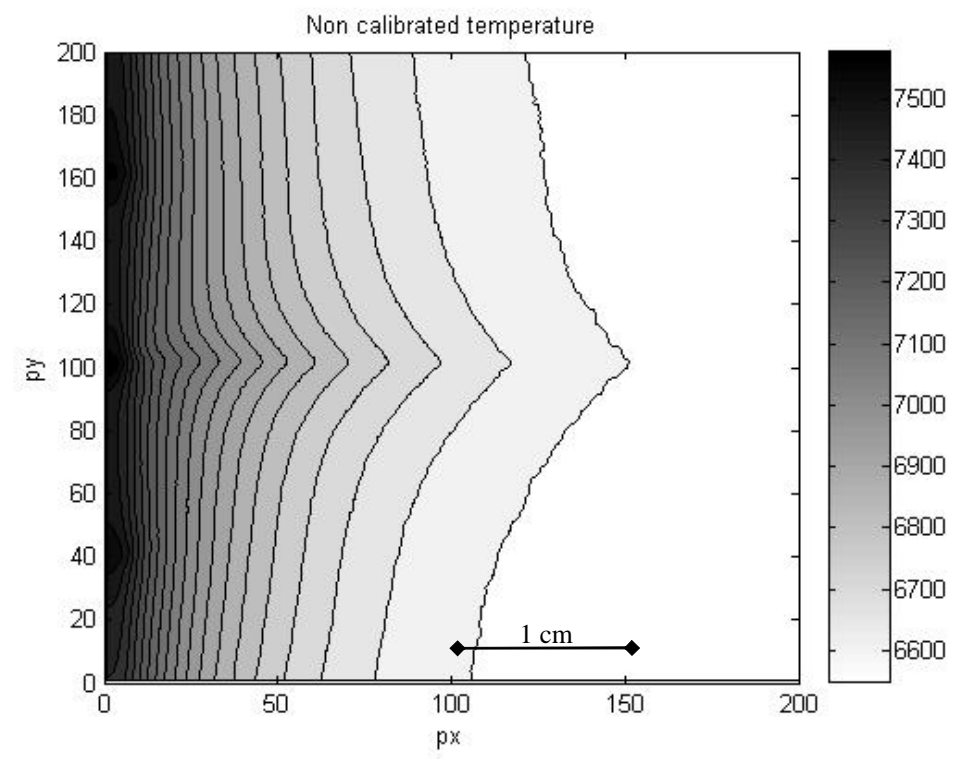

Figure 7: steady temperature field in the case of $1000 \mu \mathrm{l} / \mathrm{h}$ flow rate

Then, a flow of water is carried out at various rates with the push syringes, one example of temperature field obtained with a flow rate of $1000 \mu$ lh inside the channel is shown on figure 7 .

Such field is perturbed by the convection inside the channel and also influenced by the conduction in the plate.

One approximation of the energy conservation inside such system, analysed from the free face of the glass plate, can be considered to be mainly 2-D with local convective transport and diffusion, with the following expression:

$$
\frac{V(x, y)}{a} \frac{\partial T}{\partial x}=\left(\frac{\partial^{2} T}{\partial x^{2}}+\frac{\partial^{2} T}{\partial y^{2}}\right)+\phi(x, y)
$$

A finite difference local approximation of the previous expression yields:

$$
P e_{i, j}\left(T_{i+1, j}-T_{i, j}\right)=\left(T_{i+1, j}+T_{i-l, j}+T_{i, j+1}+T_{i, j-1}-4 T_{i, j}\right)+\phi_{i, j}
$$

Or: 
$P e_{i, j} \delta\left(T_{i, j}\right)=\Delta\left(T_{i, j}\right)+\phi_{i, j}$

With $\delta\left(T_{i, j}\right)=\left(T_{i+1, j}-T_{i, j}\right) ; \Delta\left(T_{i, j}\right)=\left(T_{i+1, j}+T_{i-l, j}+T_{i, j+1}+T_{i, j-1}-4 T_{i, j}\right)$ and where $P e_{i, j}$ is a non dimensional Peclet local number such as:

$P e_{i, j}=\frac{V_{i, j} \Delta x}{a}$

Where $V_{i, j}$ and $a$ are the apparent local velocity and thermal diffusivity respectively.

The processing of the images from figure 5 and 7 is then available by the coupling of two approximated models given by expressions [2] and [4] such as:

$$
\left\{\begin{array}{l}
\Delta\left(T_{i, j}^{0}\right)+\phi_{i, j}=0 \\
P e_{i, j} \delta\left(T_{i, j}\right)=\Delta\left(T_{i, j}\right)+\phi_{i, j}=\Delta\left(T_{i, j}-T_{i, j}^{0}\right)
\end{array}\right.
$$

where $T_{i, j}^{0}$ is the non perturbed field (at null flow rate) and $T_{i, j}$ is the perturbed field. It yields also a suitable local expression to estimate the local Peclet number:

$$
P e_{i, j}=\frac{\Delta\left(T_{i, j}-T_{i, j}^{0}\right)}{\delta\left(T_{i, j}\right)}
$$

In such expression the absolute temperature knowledge or the surface emissivity is not necessary ( $P e$ is non dimensional).

The previous expression [6] allows to consider a secondary temperature field: $T_{i, j}-T_{i, j}^{0}$ which is shown on figure 8 . The source term $\phi_{i, j}^{*}$ of such field is then perfectly known from the non perturbed field: $T_{i, j}^{0}$ such as:

$P e_{i, j} \delta\left(T_{i, j}-T_{i, j}^{0}\right)+\phi_{i, j}^{*}=\Delta\left(T_{i, j}-T_{i, j}^{0}\right)$

With $\quad \phi_{i, j}^{*}=P e_{i, j} \delta\left(T_{i, j}^{0}\right)$ 


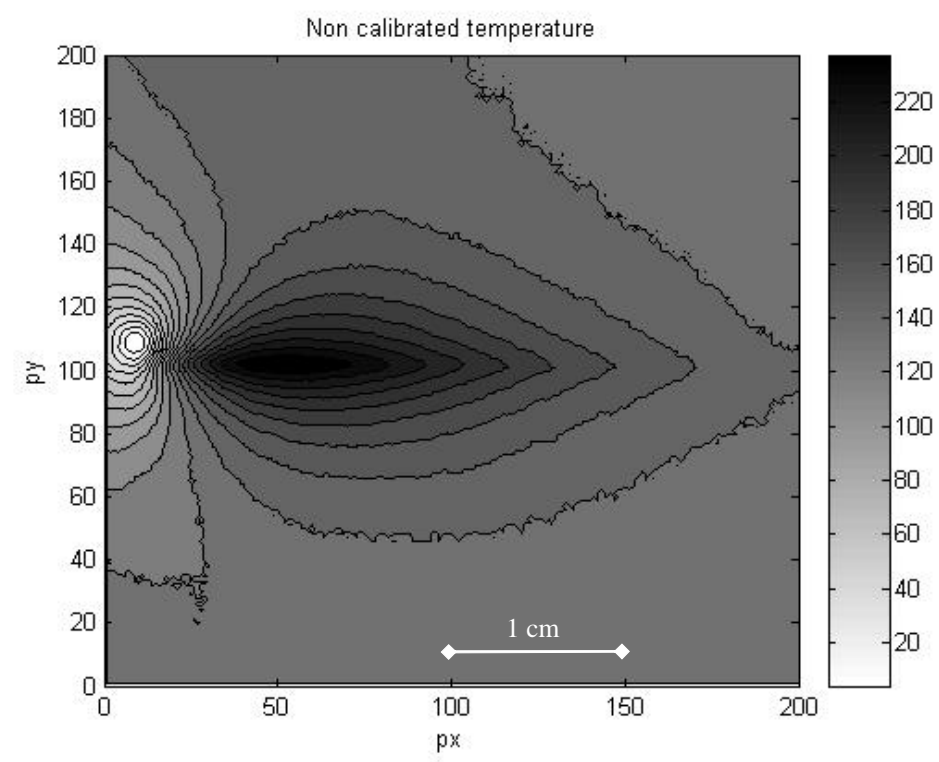

Figure 8: $\left(T-T_{0}\right)$ secondary field deduced from figures 5 and 7.

\section{3-2 Fields inversion}

Even if expressions [4] and [5] give theoretically a way to estimate the Peclet field and the source term field inside the system, the measurement noise influence must be taken into account. Unfortunately, the estimation is only possible when the derivation of the signal does not severely amplify such measurement noise. In practice, the estimation of $P e_{i, j}$ is only possible if the quantities $\Delta\left(T_{i, j}-T_{i, j}^{0}\right)$ and $\delta\left(T_{i, j}\right)$ are not too small.

The temperature measurement noise is assumed to be additive (such as: $\hat{T}_{i, j}=T_{i, j}+e_{T}$, with $\hat{T}_{i, j}$ : observable temperature, $T_{i, j}$ : real temperature, $e_{T}$ : random variable: "measurement error of $T_{i, j}$ ") and the measurement noise corresponding to each pixel is assumed to be uniform and non-dependent from the pixels in the neighbourhood (the covariance matrix of the vector of random variables corresponding to each pixel at time $t$ is diagonal and uniform such as: $\left.\operatorname{cov}\left(e_{T}=\sigma^{2} \mathbf{I}\right)\right)$. 
Then, the variance of $\Delta\left(T-T_{0}\right)_{i, j}$ is then locally about $40 \sigma^{2}$ and the variance of $\delta T_{i, j}$ is about $2 \sigma^{2}$. So, it can be assumed that $\delta T_{i, j}$ is perfectly known compared to $\Delta\left(T-T_{0}\right)_{i, j}$. Then, the variance of $P e_{i, j}$ is quite proportional to $\delta T_{i, j}^{-2}$ such as:

$\operatorname{var}\left(P e_{i, j}\right)=40 \sigma^{2} \delta T_{i, j}^{-2}$

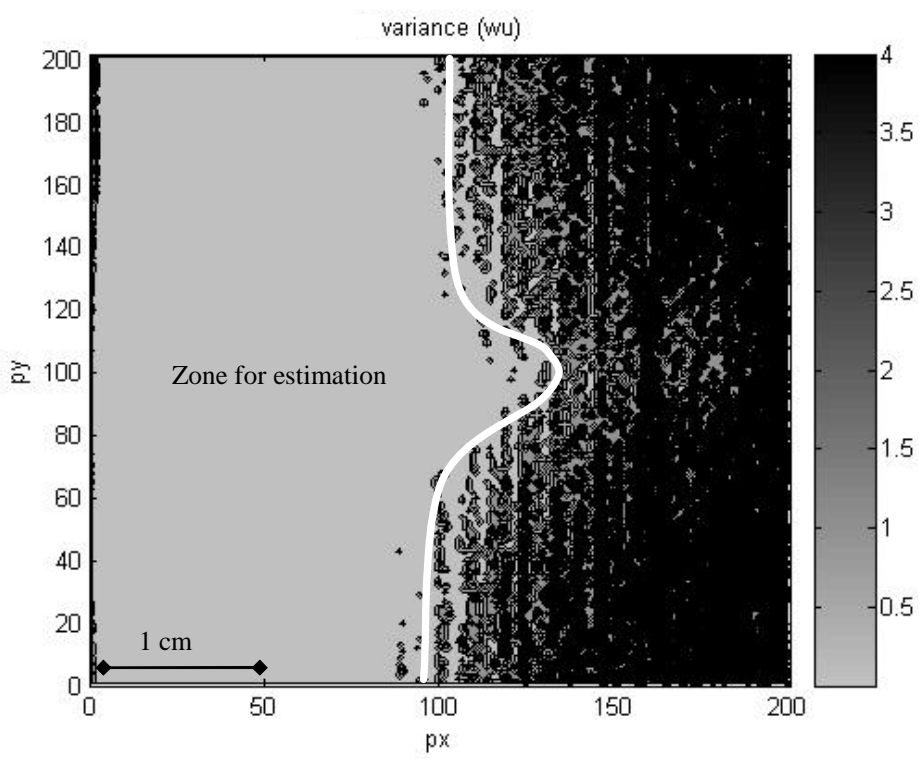

Figure 9: variance field related to the local estimation of $P e_{i, j}$ or $\delta T_{i, j}^{-2}$.

The figure 9 is showing the variance field related to the local estimation of $P e_{i, j}$ or $\delta T_{i, j}^{-2}$. It clearly shows a suitable zone for the local Peclet estimation.

Then the estimated $P e_{i, j}$ field is presented on figure 10-a. It can be noticed that such field is conveniently representing the flow only in the channel with a perceptible uniform value along the channel. It validates the simplified model. Moreover, a significant noise is found in the zone where the confidence interval is not suitable. 


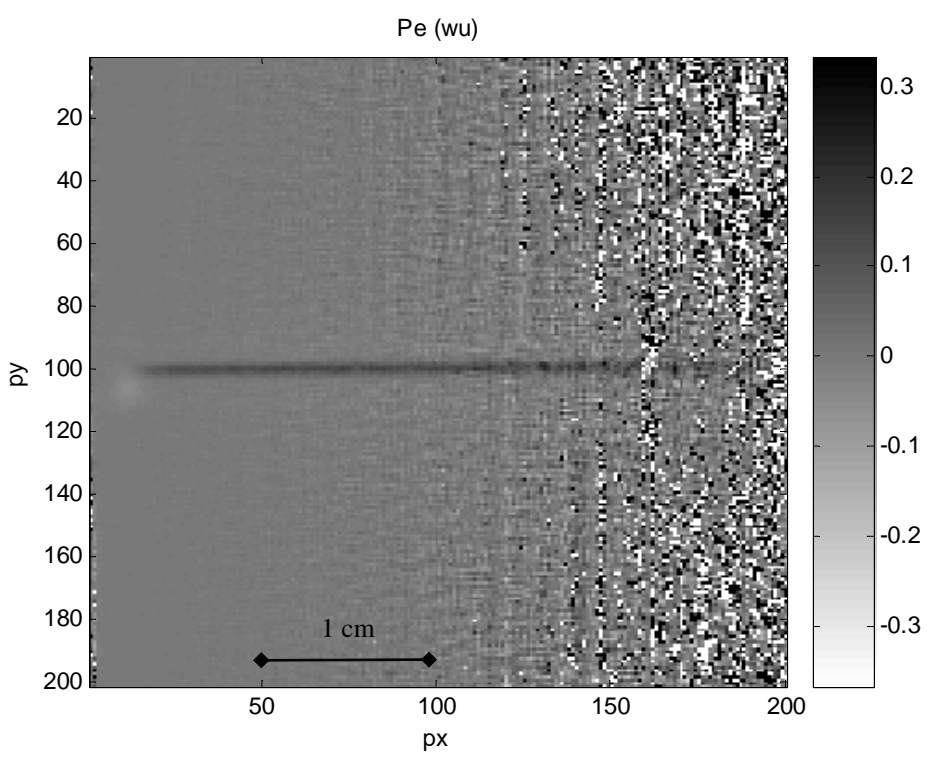

Figure 10-a: Peclet field estimation (global field at $1000 \mu \mathrm{l} / \mathrm{h}$ )

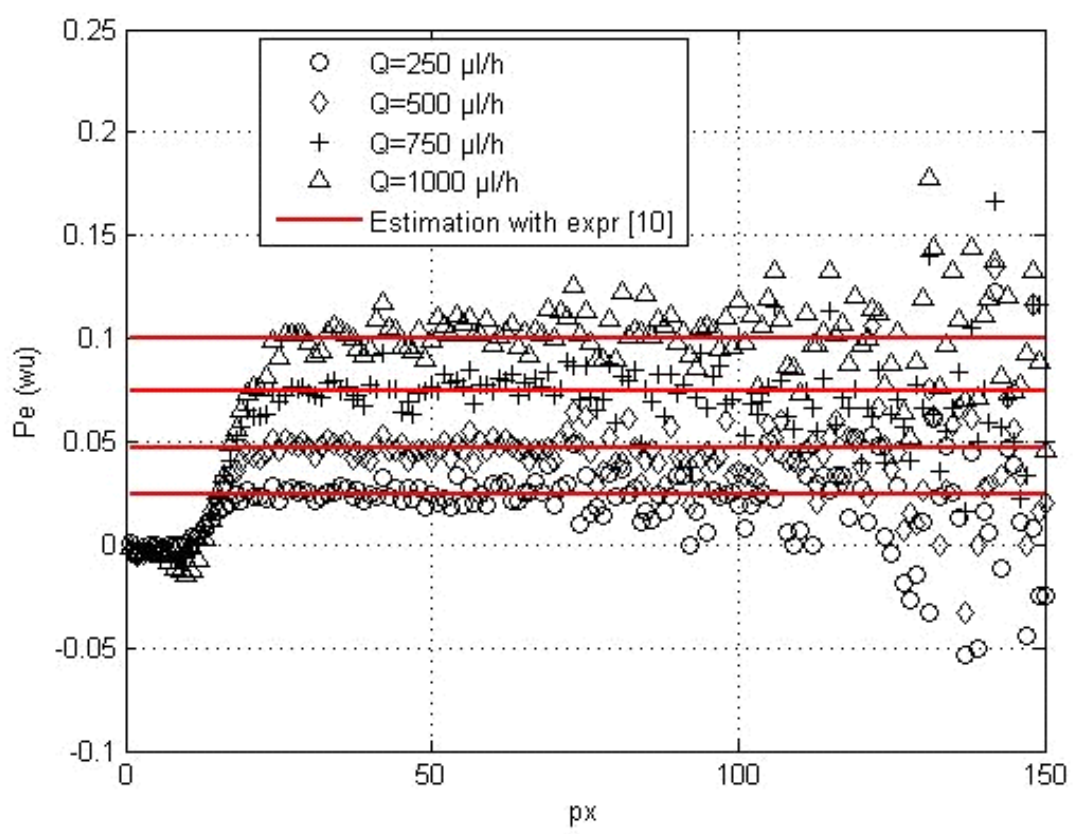

Figure 10-b: Peclet field estimation inside the channel at various flow rates from 1 to $150 \mathrm{px}$, because fig 9 . shows such a confidence zone for the estimation. 
Then, it is possible to represent the Peclet distribution obtained in the channel for various flows (figure 10-b) and global Gauss-Markov estimator is also plotted, such as:

$$
P e=\frac{\sum_{i} P e_{i} \delta T_{i}^{2}}{\sum_{i} \delta T_{i}^{2}}
$$

Only a small zone $(0<\mathrm{px}<25)$ is not verifying the simplified model given by the expression [6]. More complete models (3D, with microscopic dispersion effects, flow instability...) must be considered in the future.

With the previous assumption, the Pe and its variance are plotted for each flow rate (figure 10-c):

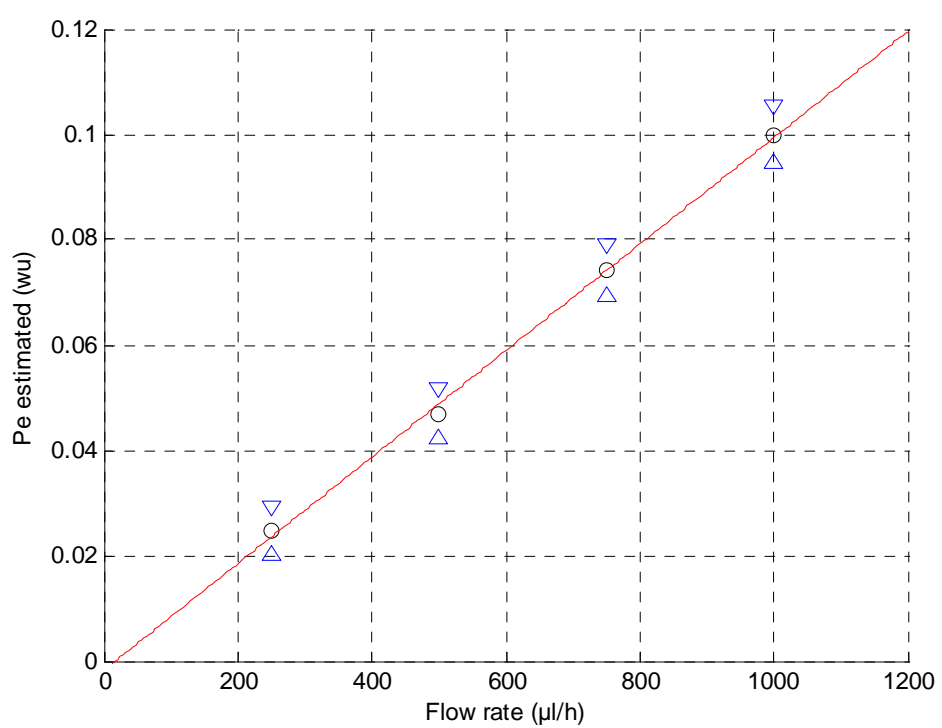

Figure 10-c: Peclet field estimation inside the channel at various flow rates.

Then, the knowledge of the Pe field allows [8] the calculation of the thermal heat source term field $\phi_{i, j}^{*}$ (figure 11-a).

By the same way, the estimation of the source term inside the channel is:

$$
\phi_{i, j}^{*}=\Delta\left(T_{i, j}-T_{i, j}^{0}\right)-\operatorname{Pe} \delta\left(T_{i, j}-T_{i, j}^{0}\right)
$$


the previous expression [11] is compared to the source term of expression [8], with a good agreement on figure 11-b. Those calculation are realised with the constant Peclet estimated before (figure 10-b) with the Gauss-Markov estimator [10].

It can be noticed that the thermal source term is present only inside the channel (figure 11-a). In the same way, the model is biased at the beginning of the channel (figure 11-b, from $\mathrm{px}=0$ to 20).



Figure 11-a: Estimated source term field from the knowledge of Peclet.

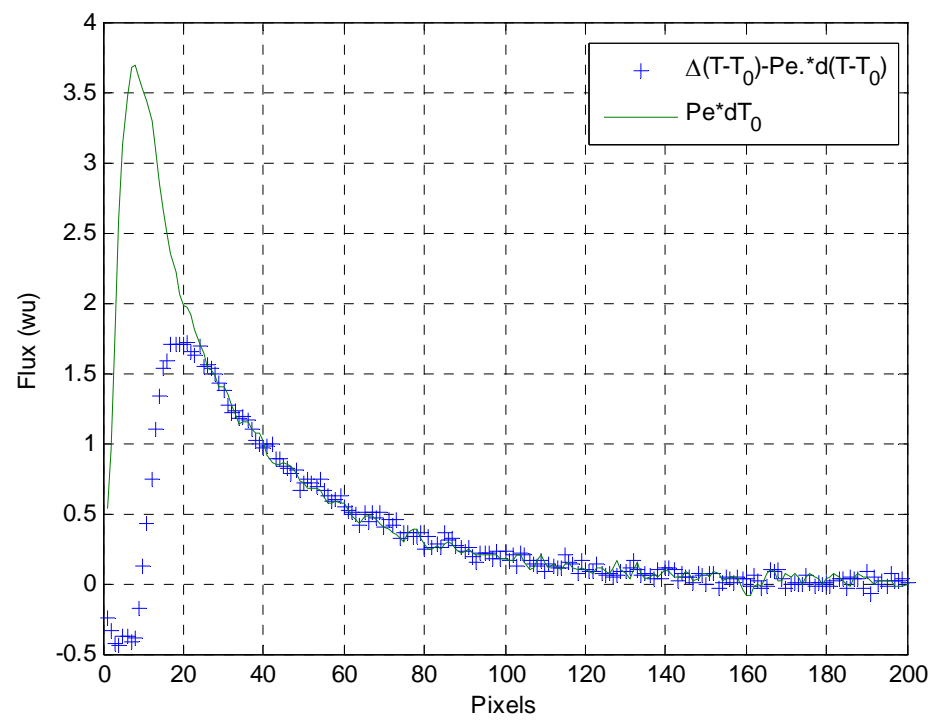


Figure 11-b: Comparison of the estimated source term from expressions [11] and [8] on measured temperature field with Peclet number estimated with [10].

\section{Study of an exothermic acid ( $\mathrm{HCl})$ - base $(\mathrm{NaOH})$ microreaction}

The previous section devoted to the estimation of the Peclet field and the previously validated simplified model can then be used in order to study specific microreactions in very near conditions of flow rate and fluids. Both liquids ( $\mathrm{HCl}$ and $\mathrm{NaOH}$, concentration of $0.25 \mathrm{~mol} / \mathrm{l}$ ) are assumed to be with the same thermophysical properties as pure water.

Then, the measurements are realised at the same flow rate as the previous experiment and the infrared camera allows the detection of the chemical heat flux created by the reaction. A temperature field measured in such conditions is shown on figure 12 .

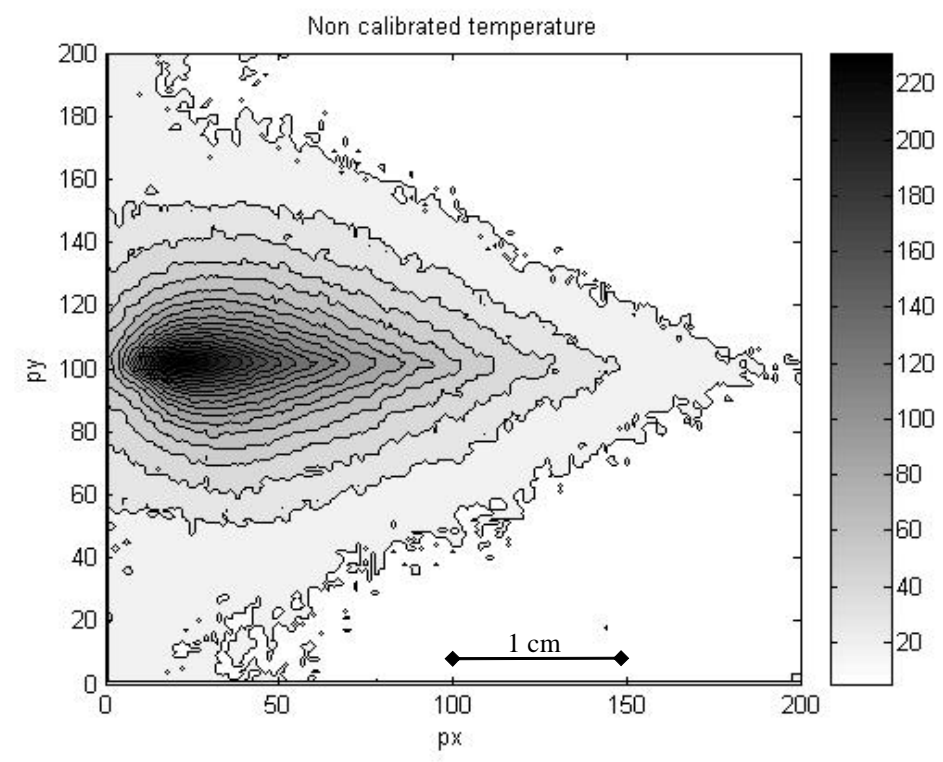

Figure 12: Temperature field measurement $T_{i, j}^{c}$ with an acid-base chemical reaction; concentration $0.25 \mathrm{~mol} / \mathrm{l}$ and flow rate $1000 \mu \mathrm{l} / \mathrm{h}$.

It is noticeable that the temperature field is very close to the previous fields studied in the calibration experiment (figure 8). The kinetic of such reaction (acid-base) is very fast. The reaction begins as soon as the products are in contact. The source term could be considered as similar as the $\phi_{i, j}^{*}$ source term generated before. 
The inversion of such field $T_{i, j}^{c}$ is then obtained from the simplified model given by expression [4] with the Pe number previously estimated. The estimation of the chemical source term field is then obtained on figures 13-a and 13-b with the expression:

$\phi_{i, j}=\Delta\left(T_{i, j}^{c}\right)-P e_{i, j} \delta\left(T_{i, j}^{c}\right)$

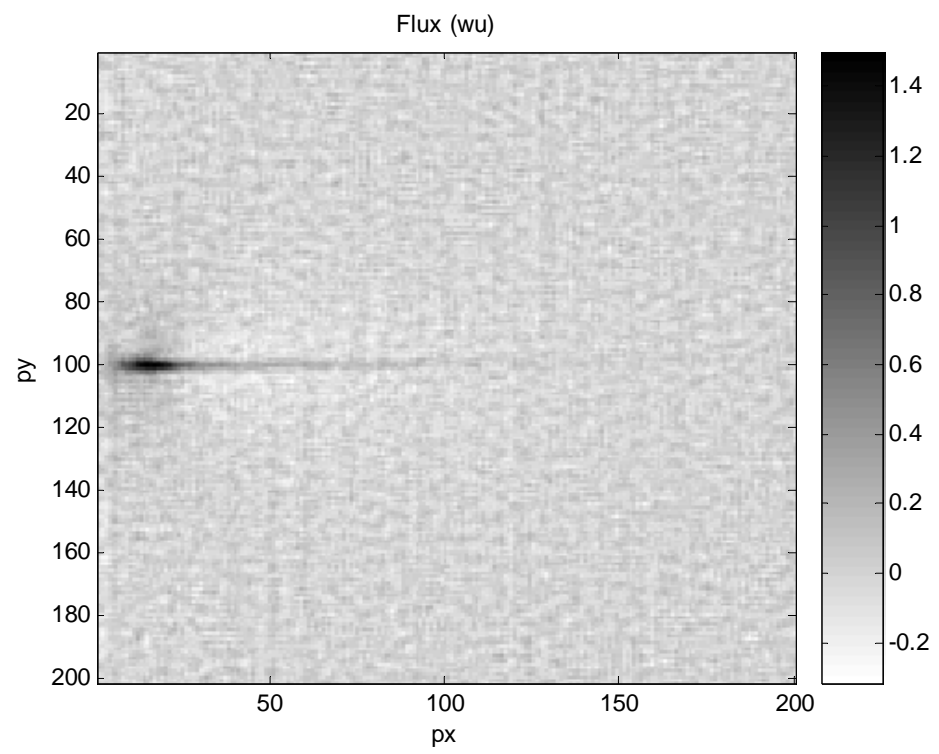

Figure 13-a: Chemical heat source field at $1000 \mu \mathrm{l} / \mathrm{h}$. 


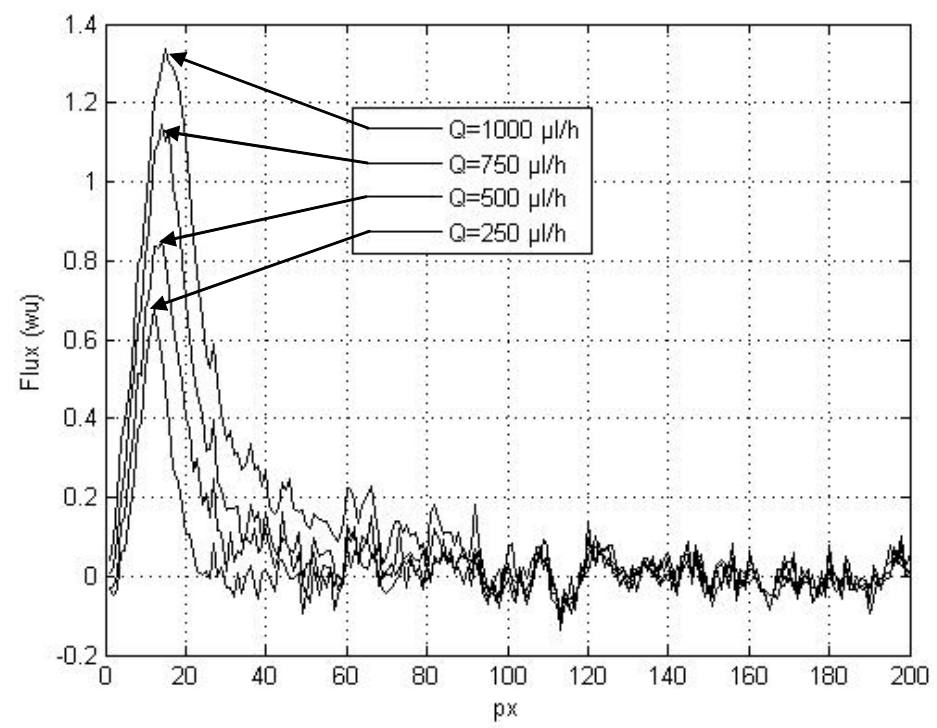

Figure 13-b: Estimated chemical heat source in the channel at different flow rates.

First, the observation of the chemical heat source field confirms that the reaction is localised inside the channel, that the consumption of the chemical reactant is very strong at the injection of the reactants. Further, inside the channel the chemical heat source depends on the flow rate. In fact, the flow rate increasing causes the rising of the spatial repartition source term. So, it is possible to increase the temporal sensitivity by adjusting the flow rate.

Such experiment is a complement of classical microcalorimetry experiments where the kinetics of reactions can be measured versus time. The time variable is here the channel length related to the time by the velocity $\left(\Delta t=\frac{\Delta x}{v}\right)$. The performance of this device is to be able to analyse chemical reaction with a time step about a few ms.

Finally, as the chemical reaction is total (flux nul at px $=120$ ), the calculation of the integral of the chemical source term for each flow rate allow the estimation of the chemical enthalpy reaction (figure 13-c): 




Figure 13-c: Integrated chemical heat source in the channel at different flow rates.

The slope of the figure 13-c is directly related to the enthalpy of the chemical reaction. The linearity of the integrated chemical flux estimated with this method versus the molar flow rate injected in the microreactor is a first result. Further, the slope of such curve can be compared to other classical global calorimetry experiments in order to calibrate the system.

\section{Conclusion and perspectives}

The simplified models developed here allow to conveniently invert the temperature field and simply analyse the measurement noise given by measurements with infrared camera on microsystem. This inversion allows the determination of both important parameter in chemical microfluidic reaction, $P e$ and $\phi$.

The main remark is that the knowledge of the absolute temperature fields (emissivity or accurate radiative properties) is non necessary to develop the processing methods presented here.

A lot of perspectives can be obtained from this preliminary work: 
First, the complete calibration can be obtained by comparison with global calorimetry experiments and such measurements are opening a complementary way to observe the kinetics of reaction

The next step of this work will be to explore the transient state estimation possibilities in order to be able to access to other fields of parameters and to study the phenomena at the entrance of the channel.

Nevertheless, steady state experiments are very convenient due to rapidity of thermal transfer at this small scale (only a few minutes). Then, such study is opening a research avenue for systematic studies (versus flow rate and reactant concentrations) for chemical microfluidic reaction.

\section{Nomenclature}

$\begin{array}{ll}x, y & \text { space coordinate } \\ \Delta x & \text { pixel size } \\ H & \text { heat losses coefficient } \\ l, L & \text { lateral sizes } \\ V(x, y), V_{i, j} & \text { fluid velocity } \\ Q & \text { Flow rate, } \mu \mathrm{h}^{-1}\end{array}$

$$
\begin{array}{ll}
a & \text { thermal diffusivity } \\
T(x, y), T_{i, j} & \text { temperature field } \\
e & \text { thickness } \\
\phi(x, y), \phi_{i, j}^{*} & \text { local source term } \\
P e_{i, j} & \text { local Peclet Number } \\
\text { wu } & \text { without unit }
\end{array}
$$

\section{References}

P. Tabeling, introduction à la microfluidique, collection échelles, Belin, 2003.

J.B. Salmon, A. Ajdari, P. Tabeling, L. Servant, D. Talaga, M. Joanicot, Imagerie Raman confocale de processus de réaction-diffusion dans des micro-canaux, Congrès SHF Microfluidique, Toulouse, p. 38, 2004.

J.M. Kölher, M. Zieren., Chip reactor for microfluidic calorimetry, Thermochim. Acta, 310, p 25-35, 1998.

K.P. Möllmann, N. Lutz and M. Vollmer, Thermography of microsystems, Inframation proceedings, ITC 104 A, 07-27, 2004.

D.C. Duffy, J.C. McDonald, Olivier J.A. Schueller, George M. Whitesides, Anal. Chem., 70, p 4974-4984, 1998. 